\title{
CR Research Square \\ Pedestrian Avoidance Method of Autonomous Personal Mobility Vehicles Considering Passenger Comfort
}

\section{Yosuke Isono ( $\square$ isonoyosuke@g.ecc.u-tokyo.ac.jp)}

The University of Tokyo Graduate School of Frontier Sciences: Tokyo Daigaku Daigakuin Shinryoiki Sosei Kagaku Kenkyuka https://orcid.org/0000-0001-8198-4790

\section{Hiroshi Yoshitake}

The University of Tokyo Graduate School of Frontier Sciences: Tokyo Daigaku Daigakuin Shinryoiki Sosei Kagaku Kenkyuka

\section{Motoki Shino}

The University of Tokyo Graduate School of Frontier Sciences: Tokyo Daigaku Daigakuin Shinryoiki Sosei Kagaku Kenkyuka

\section{Research Article}

Keywords: Personal mobility vehicle, Autonomous locomotion, Pedestrian avoidance, Comfort

Posted Date: March 19th, 2021

DOI: https://doi.org/10.21203/rs.3.rs-298102/v1

License: (c) (1) This work is licensed under a Creative Commons Attribution 4.0 International License. Read Full License 


\section{Abstract}

During the autonomous locomotion of personal mobility vehicles (PMVs) in pedestrian space, it is necessary to avoid collisions with pedestrians walking nearby. The avoidance paths of the PMVs are affected by the behavior of the pedestrians, which may also affect passenger comfort. In this study, a local path planning method considering passenger comfort is proposed to design comfortable pedestrian avoidance strategies during autonomous locomotion of PMVs in pedestrian space. First, pedestrian behaviors that affect passenger comfort are investigated by evaluating the comfort in pedestrian avoidance scenarios with different avoidance methods and pedestrian behavior. Next, requirements for a pedestrian avoidance method considering comfort are set based on the behaviors affecting passenger comfort. Finally, a novel path planning method satisfying the requirements is proposed. It is confirmed that the proposed method can generate comfortable paths in pedestrian space, and the validity of the proposed method is examined by a subject experiment.

\section{Full Text}

This preprint is available for download as a PDF.

\section{Figures}

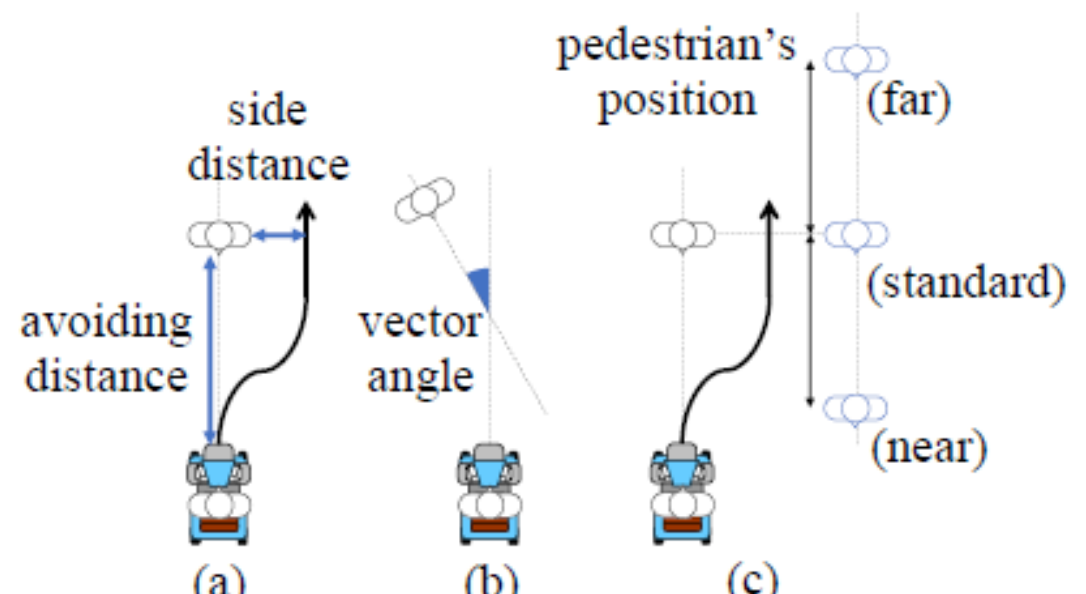

Figure 1

Parameters of avoidance method and pedestrian behavior 

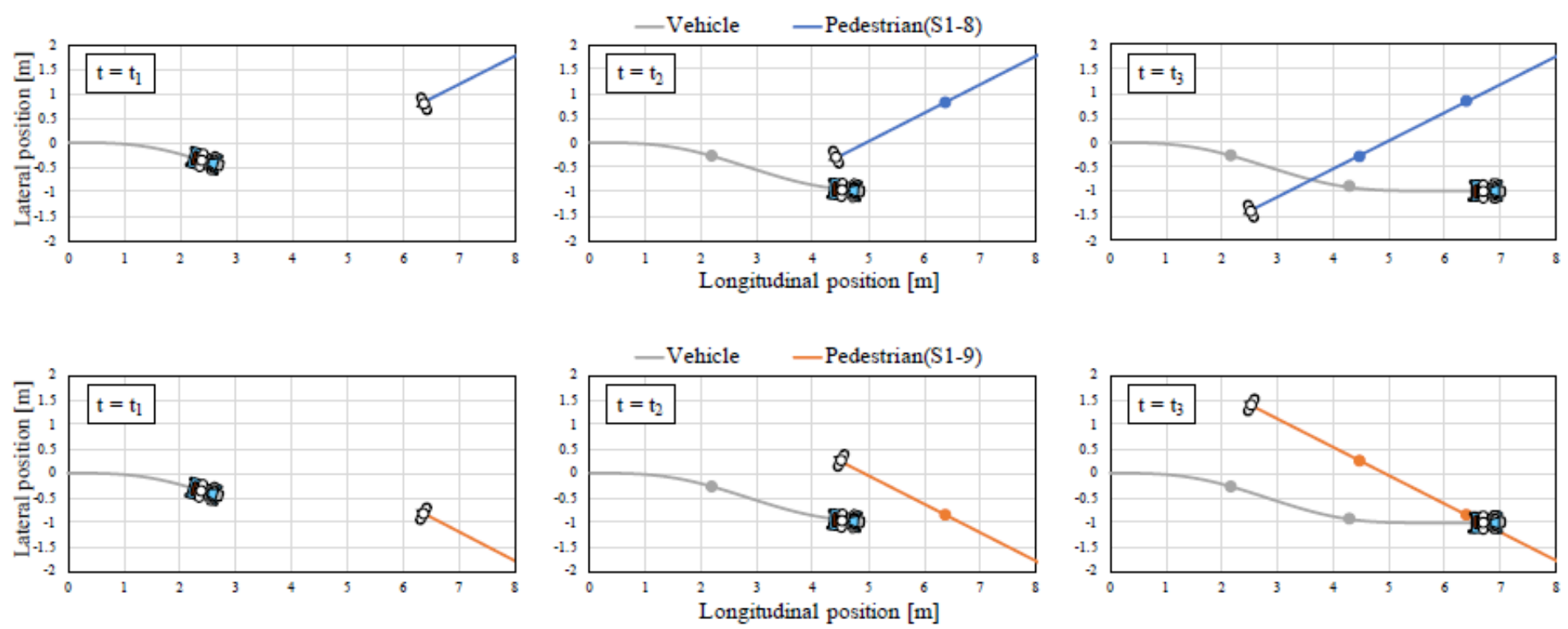

Figure 2

Pedestrian paths with different vector angles

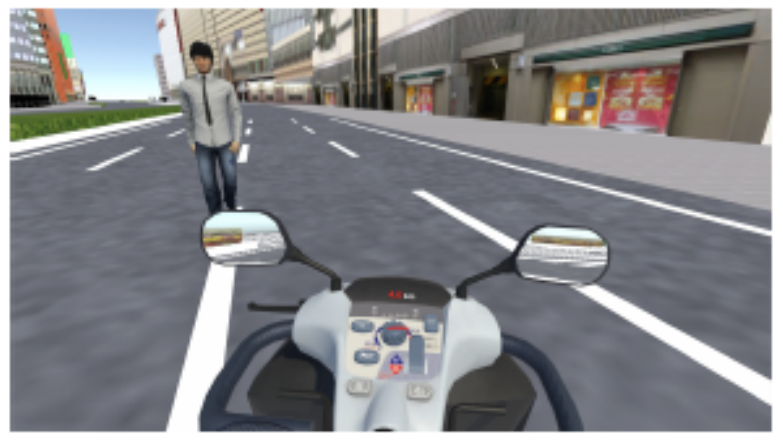

Figure 3

Image inside head-mounted display

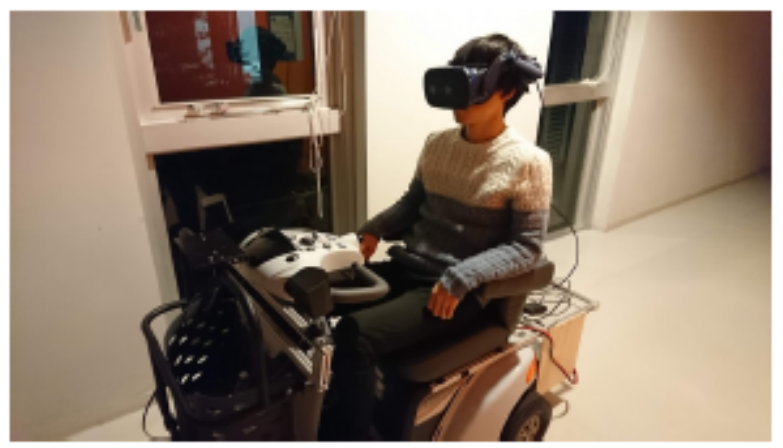

Figure 4

Experiment setup 


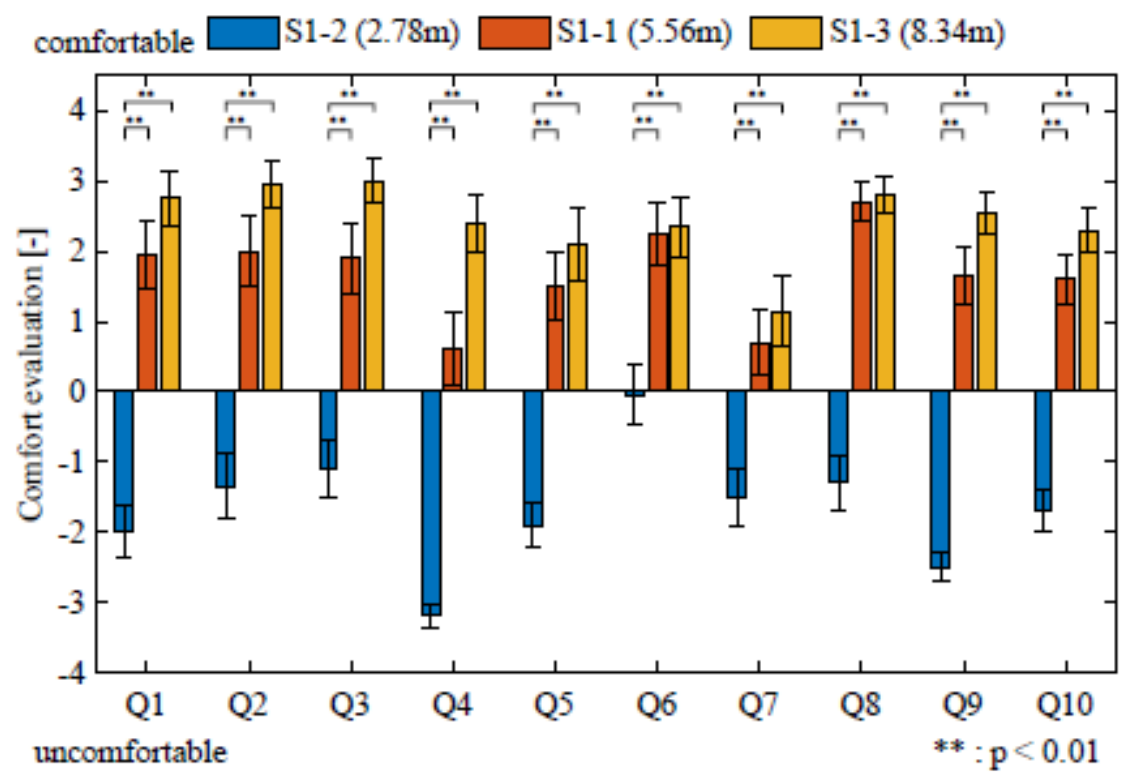

Figure 5

Influence of avoiding distance on comfort evaluation

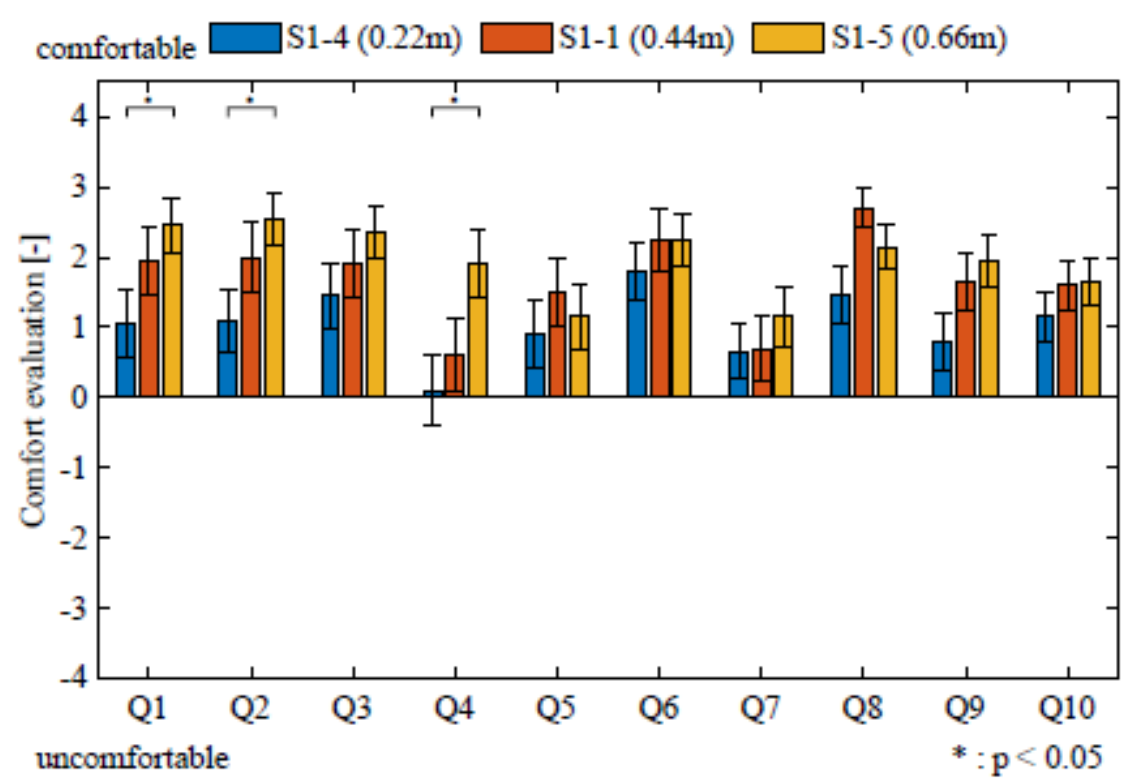

Figure 6

Influence of side distance on comfort evaluation 


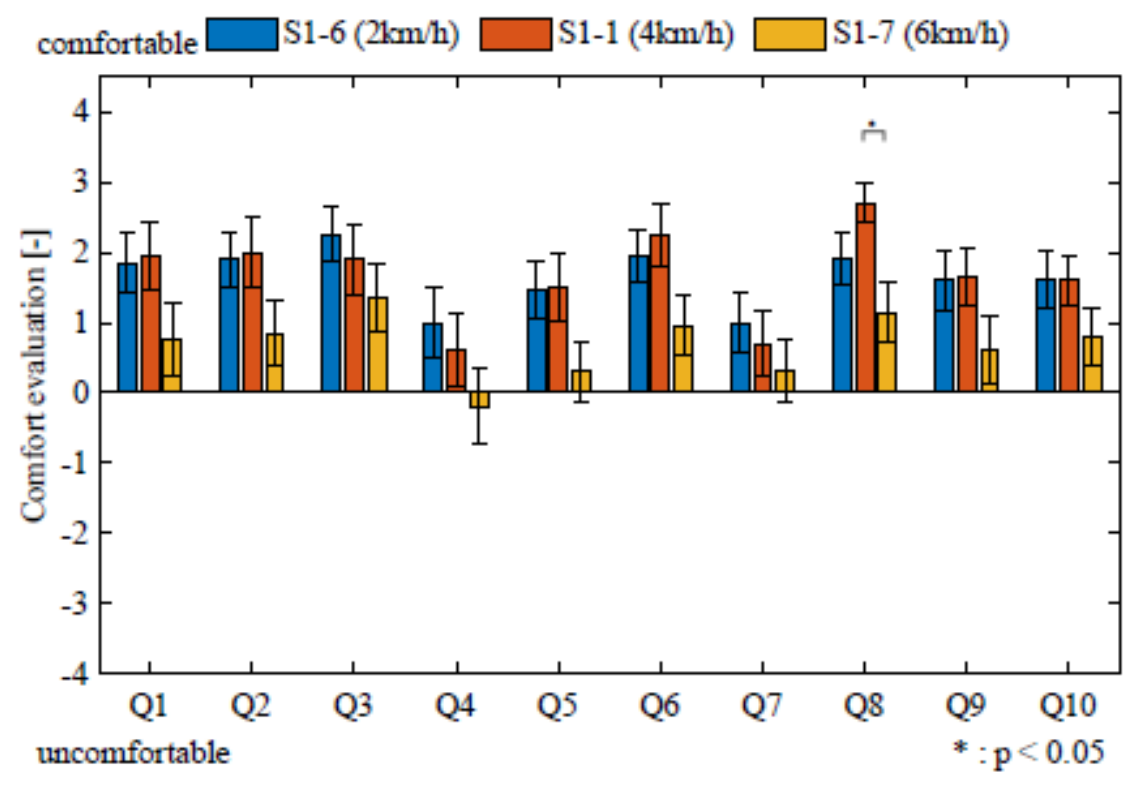

Figure 7

Influence of pedestrian speed on comfort evaluation

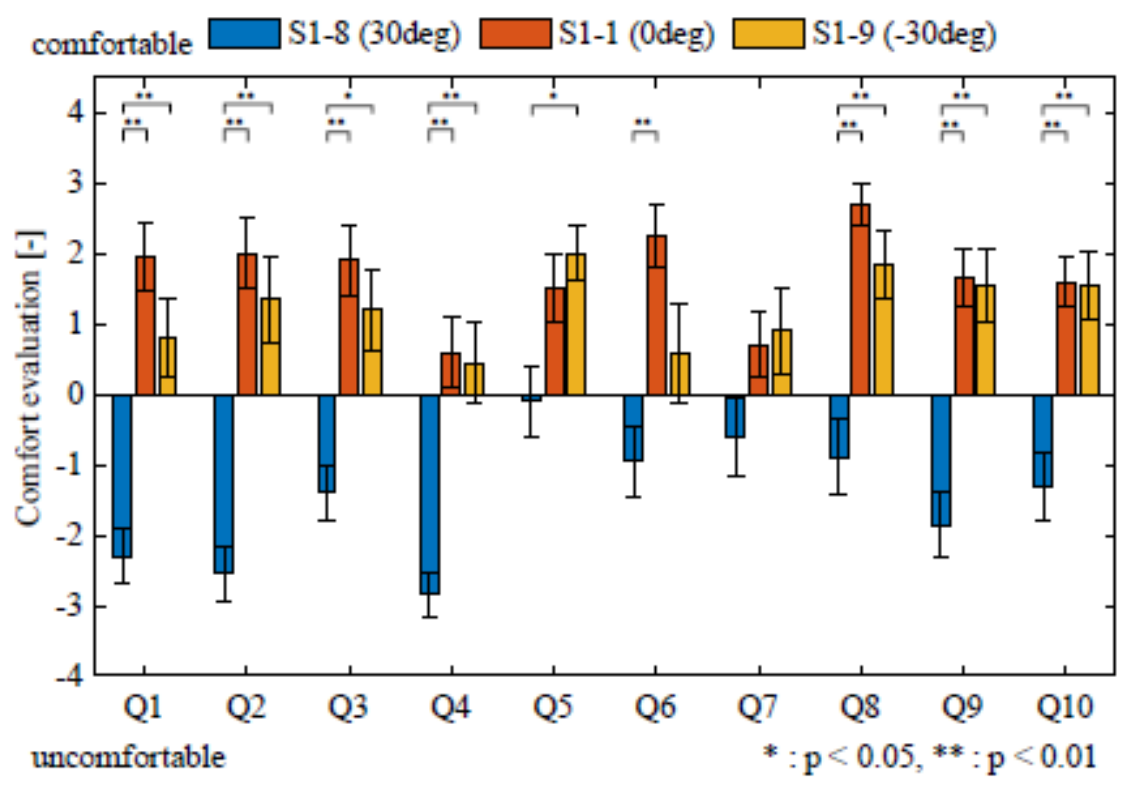

Figure 8

Influence of vector angle on comfort evaluation 


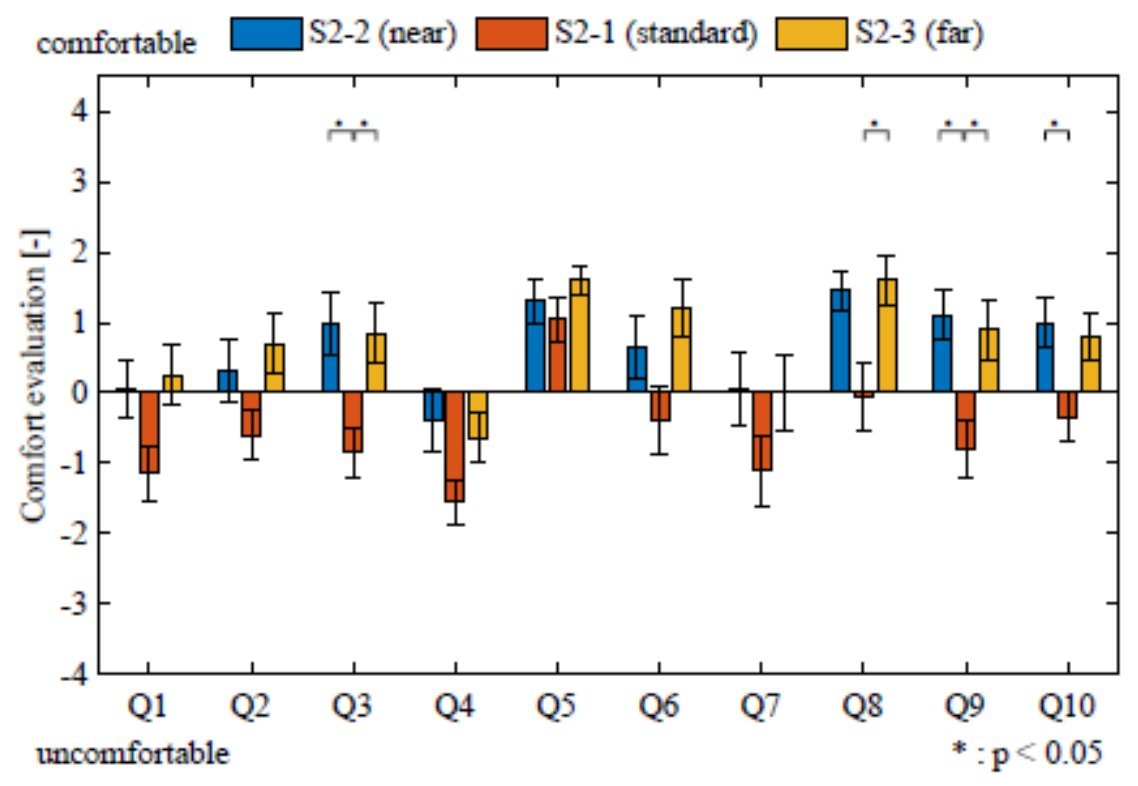

Figure 9

Influence of the second pedestrian position on comfort evaluation

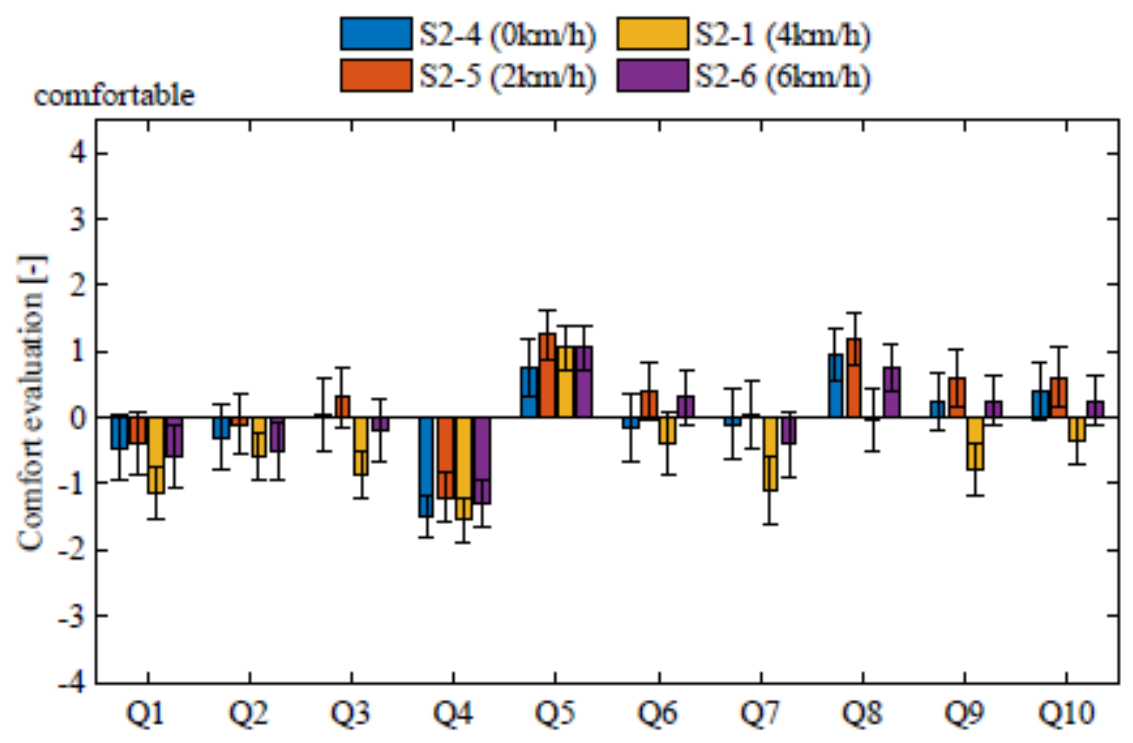

uncomfortable

Figure 10

Influence of the second pedestrian speed on comfort evaluation 


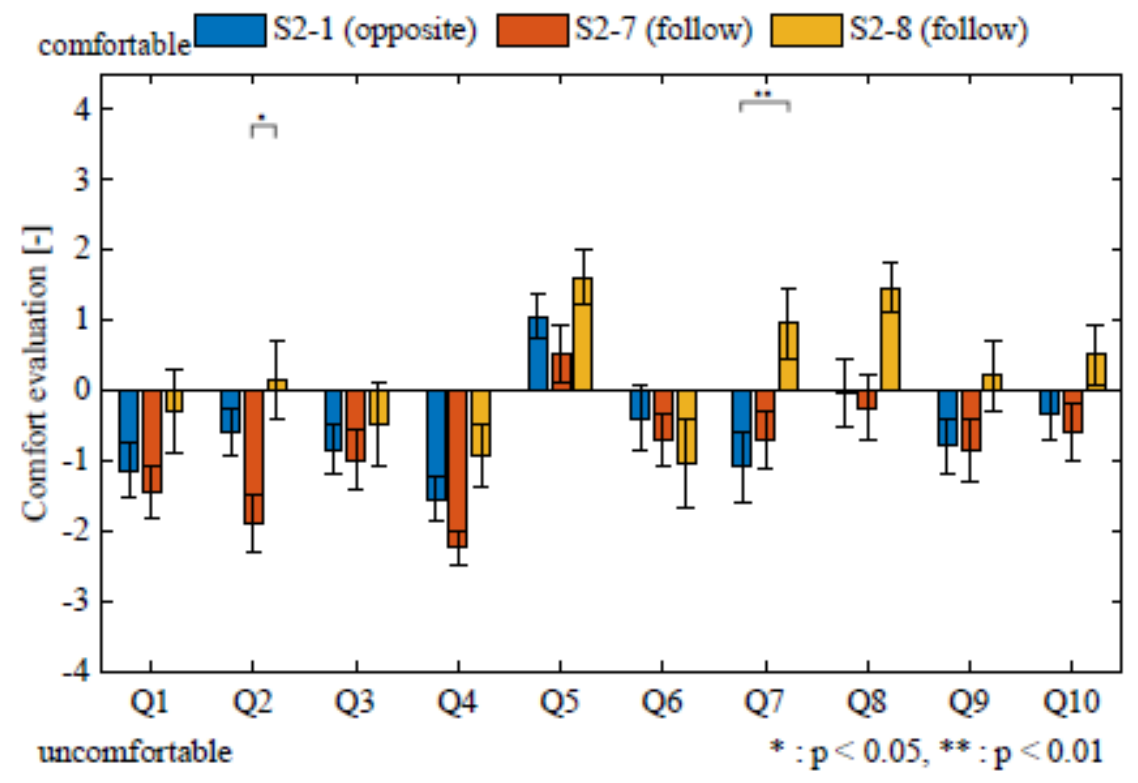

Figure 11

Influence of the second pedestrian's direction of travel on comfort evaluation

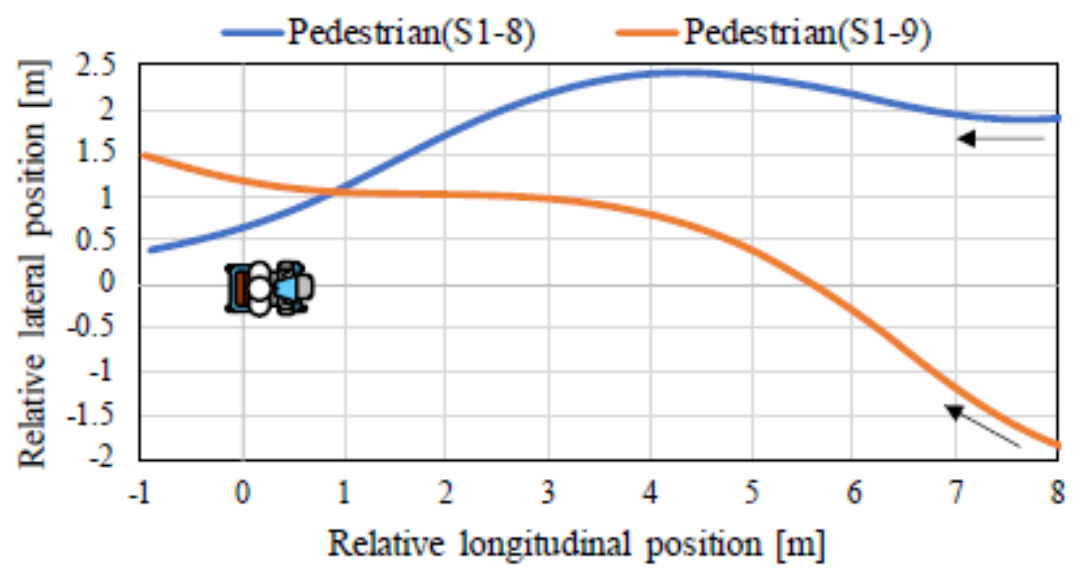

Figure 12

Pedestrian route in vehicle relative coordinates

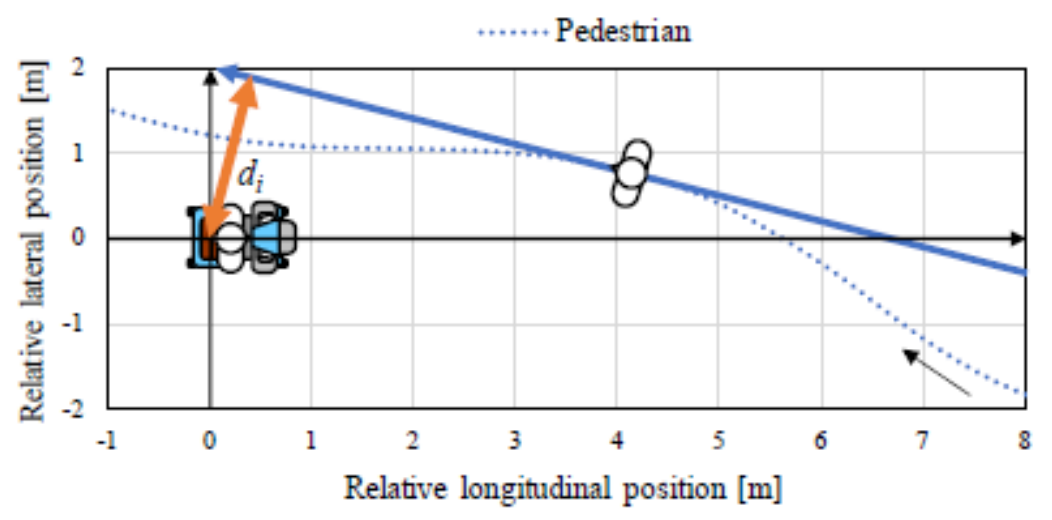


Figure 13

Definition of di

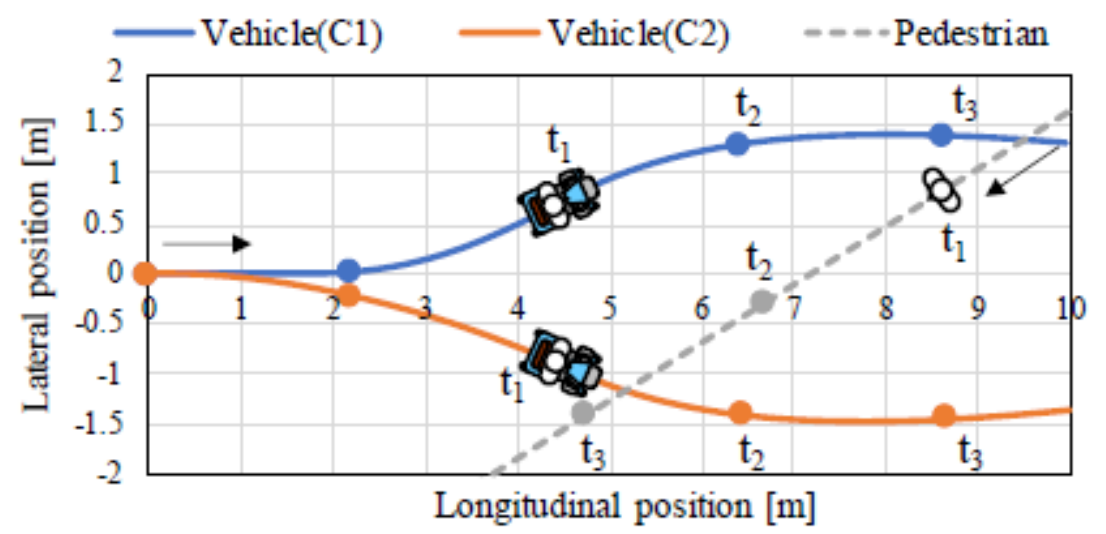

Figure 14

Vehicle paths avoiding a crossing pedestrian ( $\mathrm{t} 1, \mathrm{t} 2$, and $\mathrm{t} 3$ represent the position at the same time)

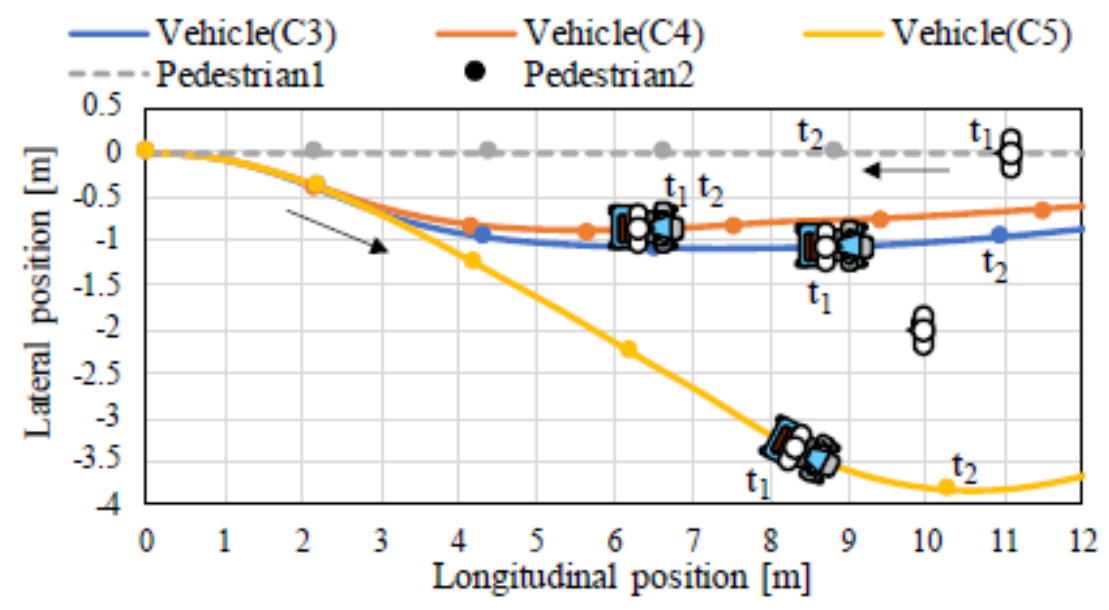

\section{Figure 15}

Vehicle paths avoiding two pedestrians (t1 and $\mathrm{t} 2$ represent the position at the same time) 


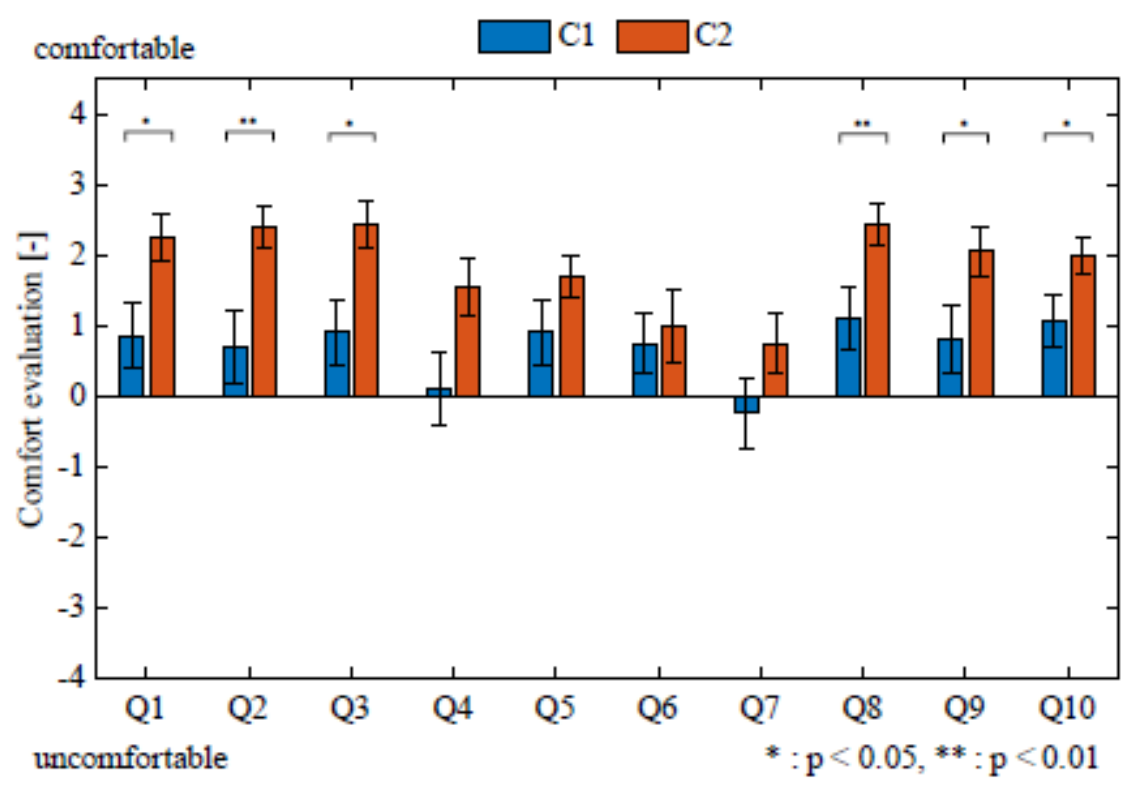

Figure 16

Comfort evaluation of different paths avoiding a crossing pedestrian

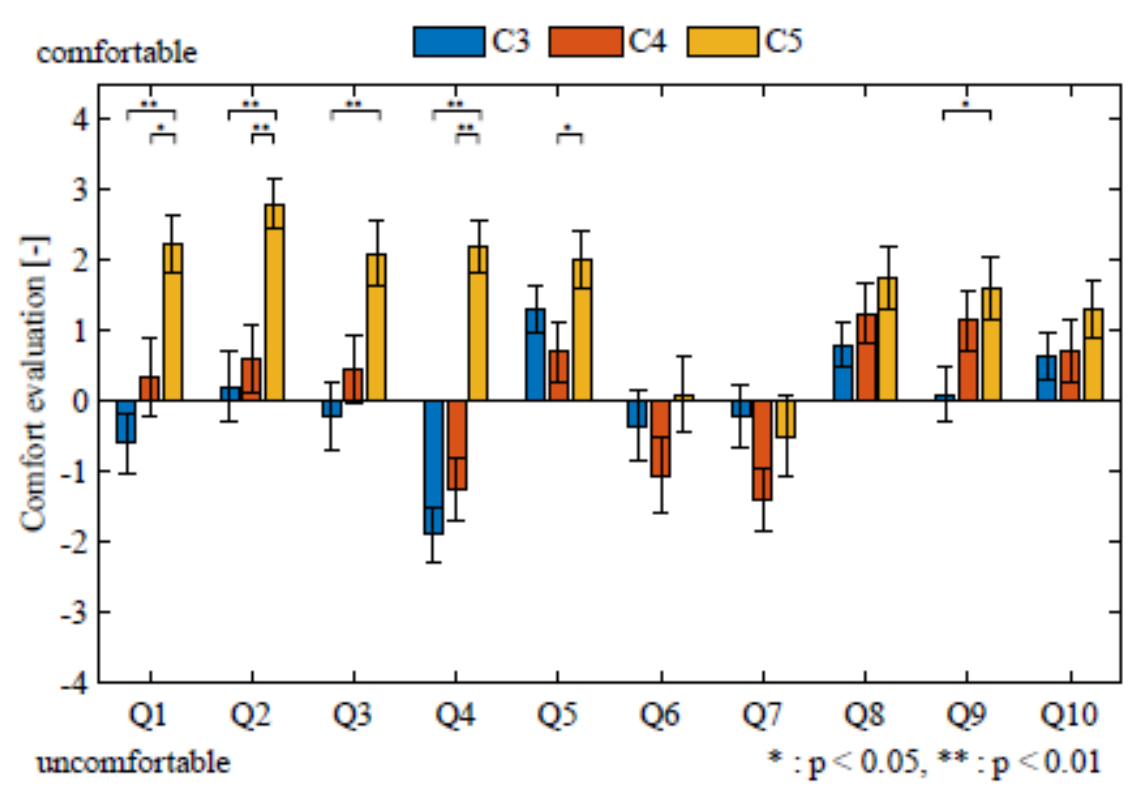

Figure 17

Comfort evaluation of different paths avoiding two pedestrians 